\title{
Inelastic $\mathrm{Na}+\mathrm{H}$ collision data for non-LTE applications in stellar atmospheres (Research Note)
}

\author{
P. S. Barklem ${ }^{1}$, A. K. Belyaev², A. S. Dickinson ${ }^{3}$, and F. X. Gadéa ${ }^{4}$ \\ 1 Department of Physics and Astronomy, Uppsala University, Box 515, 75120 Uppsala, Sweden \\ e-mail: Paul.Barklem@fysast.uu.se \\ 2 Department of Theoretical Physics, Herzen University, St. Petersburg 191186, Russia \\ School of Chemistry, Newcastle University, NE1 7RU Newcastle upon Tyne, UK \\ ${ }^{4}$ Laboratoire de Chimie et Physique Quantique, UMR 5626 du CNRS, IRSAMC, Université Paul Sabatier, 118 rte de Narbonne, \\ 31062 Toulouse, France
}

Received 4 June 2010 / Accepted 24 June 2010

\section{ABSTRACT}

\begin{abstract}
Rate coefficients for inelastic $\mathrm{Na}+\mathrm{H}$ collisions are calculated for all transitions between the ten levels up to and including the ionic state (ion-pair production), namely $\mathrm{Na}(3 \mathrm{~s}, 3 \mathrm{p}, 4 \mathrm{~s}, 3 \mathrm{~d}, 4 \mathrm{p}, 5 \mathrm{~s}, 4 \mathrm{~d}, 4 \mathrm{f}, 5 \mathrm{p})+\mathrm{H}(1 \mathrm{~s})$ and $\mathrm{Na}^{+}+\mathrm{H}^{-}$. The calculations are based on recent full quantum scattering cross-section calculations. The data are needed for non-LTE applications in cool astrophysical environments, especially cool stellar atmospheres, and are presented for a temperature range of 500-8000 K. From consideration of the sensitivity of the cross-sections to input quantum chemical data and the results of different methods for the scattering calculations, a measure of the possible uncertainties in the rate coefficients is estimated.
\end{abstract}

Key words. atomic data - line: formation - stars: abundances

\section{Introduction}

Lack of accurate data for collision processes needed for reliable non-LTE line formation calculations in cool star atmospheres, especially processes involving hydrogen atom and electron impacts, poses a major source of uncertainty for stellar abundance analyses; e.g. Lambert (1993); Kiselman (2001); Asplund (2005). For hydrogen, the situation is particularly poor. The possible importance of collisions with neutral hydrogen in non-LTE line formation calculations was first pointed out by Steenbock \& Holweger (1984) in their study of the statistical equilibrium of Li in cool stars. Although inelastic processes due to hydrogen collisions are expected to be much less efficient than those due to electrons, the much greater abundance of hydrogen atoms may overcome this reduced efficiency: in the line forming regions of a solar-type star the abundance of hydrogen atoms is typically four orders of magnitude greater than that of electrons, even more in metal-poor stars.

At the time of Steenbock and Holweger's study there was practically no reliable experimental or theoretical work on inelastic hydrogen collision processes; however, the situation has been improving slowly but steadily over the quarter of a century since then. Their work prompted an experimental study by Fleck et al. (1991) of $\mathrm{Na}(3 \mathrm{~s})+\mathrm{H} \rightarrow \mathrm{Na}(3 \mathrm{p})+\mathrm{H}$ at low (15-1500 eV) energies, though due to experimental difficulties not down to near the threshold $(2.1 \mathrm{eV}$ for this case), which is the relevant regime for the temperatures of interest in cool stars. Revised experimental data, including results down to $10 \mathrm{eV}$, were presented in Belyaev et al. (1999). This work was followed by a number of theoretical studies involving some of the present authors. First, quantum scattering calculations were performed for $\mathrm{Na}(3 \mathrm{~s})+\mathrm{H} \rightarrow \mathrm{Na}(3 \mathrm{p}, 4 \mathrm{~s})+\mathrm{H}$ down to the threshold (Belyaev et al. 1999) and found good agreement with the experimental results above $10 \mathrm{eV}$. This work on $\mathrm{Na}+\mathrm{H}$ was followed by calculations for $\mathrm{Li}+\mathrm{H}$ (Belyaev \& Barklem 2003) based on quantum-chemical data calculated by some of us (Croft et al. 1999). This was followed by astrophysical application (Barklem et al. 2003; Lind et al. 2009), where it was found that excitation collisions $\mathrm{Li}(n l)+\mathrm{H} \rightarrow \mathrm{Li}\left(n^{\prime} l^{\prime}\right)+\mathrm{H}$ were unimportant, yet the ion-pair production and mutual-neutralisation process $\mathrm{Li}(3 \mathrm{~s})+\mathrm{H} \rightleftharpoons \mathrm{Li}^{+}+\mathrm{H}^{-}$(often referred to as charge exchange in astrophysics) was found to be rather important, resulting in changes in spectral line strengths of around $20 \%$ in cool, metalpoor, sub-giant stars.

In a recent paper (Belyaev et al. 2010) we revisited lowenergy $\mathrm{Na}+\mathrm{H}$ collisions, since for astrophysical non-LTE modelling of $\mathrm{Na}$ line formation data for transitions between all possible $\mathrm{Na}$ levels are needed, while the earlier experimental and theoretical studies dealt primarily with the resonance transition (which corresponds to the $\mathrm{Na} \mathrm{D}$ lines). Details of the calculations can be found in that paper. Cross-sections for transitions between all ten levels up to and including the ionic state (ion-pair production) for collision energies from threshold to $10 \mathrm{eV}$ were presented. In fact, cross-sections were calculated up to collision energies of $100 \mathrm{eV}$; however, the results at energies higher than $10 \mathrm{eV}$ are of little importance at the temperatures of interest. The purpose of this research note is to present rate coefficients calculated from these cross-sections, as these rate coefficients are needed for non-LTE applications such as in cool stars.

\section{Collision rate coefficients}

The rate coefficients, $\langle\sigma v\rangle$, for excitation and deexcitation processes $\mathrm{Na}(n l)+\mathrm{H}(1 \mathrm{~s}) \rightleftharpoons \mathrm{Na}\left(n^{\prime} l^{\prime}\right)+\mathrm{H}(1 \mathrm{~s})$, and for the ionpair production and mutual-neutralisation processes involving 
A\&A 519, A20 (2010)

Table 1. Rate coefficients $\langle\sigma v\rangle$, in units of $\mathrm{cm}^{3} \mathrm{~s}^{-1}$, for selected temperatures in the range $T=500-8000 \mathrm{~K}$, for the excitation and deexcitation processes $\mathrm{Na}(n l)+\mathrm{H}(1 \mathrm{~s}) \rightarrow \mathrm{Na}\left(n^{\prime} l^{\prime}\right)+\mathrm{H}(1 \mathrm{~s})$, or where indicated ion-pair production $\mathrm{Na}(n l)+\mathrm{H}(1 \mathrm{~s}) \rightarrow \mathrm{Na}^{+}\left(2 \mathrm{~s}^{2} 2 \mathrm{p}^{6}\right)+\mathrm{H}^{-}$and mutual neutralisation $\mathrm{Na}^{+}\left(2 \mathrm{~s}^{2} 2 \mathrm{p}^{6}\right)+\mathrm{H}^{-} \rightarrow \mathrm{Na}\left(n^{\prime} l^{\prime}\right)+\mathrm{H}(1 \mathrm{~s})$.

\begin{tabular}{|c|c|c|c|c|c|c|c|c|c|c|}
\hline $\begin{array}{l}\text { Initial } \\
\text { state } n l\end{array}$ & $3 \mathrm{~s}$ & $3 p$ & $4 \mathrm{~s}$ & $3 \mathrm{~d}$ & $\begin{array}{c}\text { inal state } n^{\prime} l \\
4 \mathrm{p}\end{array}$ & $5 \mathrm{~s}$ & $4 d$ & $4 f$ & $5 p$ & $\mathrm{Na}^{+}+\mathrm{H}^{-}$ \\
\hline $3 \mathrm{~s}$ & - & $1.07 \mathrm{E}-37$ & $1.09 \mathrm{E}-50$ & $3.41 \mathrm{E}-54$ & $\begin{array}{c}500 \mathrm{~K} \\
8.22 \mathrm{E}-56\end{array}$ & $2.75 \mathrm{E}-61$ & $8.05 \mathrm{E}-64$ & $2.76 \mathrm{E}-64$ & $9.36 \mathrm{E}-66$ & $5.64 \mathrm{E}-60$ \\
\hline $3 p$ & $5.81 \mathrm{E}-17$ & - & $1.77 \mathrm{E}-23$ & $5.45 \mathrm{E}-28$ & $2.03 \mathrm{E}-29$ & $8.25 \mathrm{E}-36$ & $9.86 \mathrm{E}-40$ & $5.60 \mathrm{E}-40$ & $3.41 \mathrm{E}-43$ & $4.64 \mathrm{E}-34$ \\
\hline $4 \mathrm{~s}$ & $1.65 \mathrm{E}-18$ & $4.93 \mathrm{E}-12$ & - & $4.15 \mathrm{E}-14$ & $7.63 \mathrm{E}-16$ & $2.77 \mathrm{E}-22$ & $2.93 \mathrm{E}-27$ & $2.61 \mathrm{E}-27$ & $6.14 \mathrm{E}-30$ & $4.14 \mathrm{E}-20$ \\
\hline $3 d$ & $2.02 \mathrm{E}-18$ & $5.95 \mathrm{E}-13$ & $1.62 \mathrm{E}-10$ & - & $6.19 \mathrm{E}-13$ & $3.91 \mathrm{E}-20$ & $6.67 \mathrm{E}-24$ & $2.21 \mathrm{E}-24$ & $3.40 \mathrm{E}-27$ & $2.20 \mathrm{E}-17$ \\
\hline $4 p$ & $1.92 \mathrm{E}-18$ & $8.72 \mathrm{E}-13$ & $1.17 \mathrm{E}-10$ & $2.44 \mathrm{E}-11$ & - & $1.42 \mathrm{E}-14$ & $7.98 \mathrm{E}-19$ & $4.21 \mathrm{E}-19$ & $2.20 \mathrm{E}-23$ & $2.53 \mathrm{E}-16$ \\
\hline $5 \mathrm{~s}$ & $8.97 \mathrm{E}-20$ & $4.96 \mathrm{E}-15$ & $5.96 \mathrm{E}-13$ & $2.15 \mathrm{E}-14$ & $1.99 \mathrm{E}-10$ & - & $3.45 \mathrm{E}-15$ & $8.97 \mathrm{E}-16$ & $2.01 \mathrm{E}-18$ & $5.75 \mathrm{E}-15$ \\
\hline $4 d$ & $2.60 \mathrm{E}-21$ & $5.87 \mathrm{E}-18$ & $6.24 \mathrm{E}-17$ & $3.64 \mathrm{E}-17$ & $1.10 \mathrm{E}-13$ & $3.42 \mathrm{E}-14$ & & $6.18 \mathrm{E}-10$ & $1.83 \mathrm{E}-16$ & $8.69 \mathrm{E}-17$ \\
\hline $4 \mathrm{f}$ & $7.34 \mathrm{E}-22$ & $2.75 \mathrm{E}-18$ & $4.57 \mathrm{E}-17$ & $9.91 \mathrm{E}-18$ & $4.80 \mathrm{E}-14$ & $7.32 \mathrm{E}-15$ & $5.09 \mathrm{E}-10$ & - & $1.64 \mathrm{E}-16$ & $5.80 \mathrm{E}-17$ \\
\hline $5 p$ & $2.08 \mathrm{E}-22$ & $1.40 \mathrm{E}-20$ & $9.02 \mathrm{E}-19$ & $1.28 \mathrm{E}-19$ & $2.10 \mathrm{E}-17$ & $1.37 \mathrm{E}-16$ & $1.26 \mathrm{E}-15$ & $1.38 \mathrm{E}-15$ & - & $7.48 \mathrm{E}-19$ \\
\hline $\mathrm{Na}^{+}+\mathrm{H}^{-}$ & $3.67 \mathrm{E}-15$ & $5.55 \mathrm{E}-10$ & $1.77 \mathrm{E}-07$ & $2.41 \mathrm{E}-08$ & $\begin{array}{c}7.04 \mathrm{E}-09 \\
2000 \mathrm{~K}\end{array}$ & $1.15 \mathrm{E}-11$ & $1.75 \mathrm{E}-14$ & $1.42 \mathrm{E}-14$ & $2.18 \mathrm{E}-17$ & \\
\hline $3 \mathrm{~s}$ & - & $1.71 \mathrm{E}-21$ & $7.65 \mathrm{E}-26$ & $3.82 \mathrm{E}-27$ & $7.85 \mathrm{E}-28$ & $7.45 \mathrm{E}-30$ & $1.09 \mathrm{E}-31$ & $8.46 \mathrm{E}-32$ & $2.76 \mathrm{E}-31$ & $5.51 \mathrm{E}-27$ \\
\hline $3 p$ & $7.86 \mathrm{E}-17$ & - & $4.35 \mathrm{E}-15$ & $1.51 \mathrm{E}-16$ & $4.25 \mathrm{E}-17$ & $2.63 \mathrm{E}-20$ & $8.94 \mathrm{E}-24$ & $8.19 \mathrm{E}-24$ & $2.72 \mathrm{E}-25$ & $5.87 \mathrm{E}-17$ \\
\hline $4 \mathrm{~s}$ & $8.48 \mathrm{E}-18$ & $7.21 \mathrm{E}-12$ & - & $7.36 \mathrm{E}-11$ & $1.08 \mathrm{E}-11$ & $1.95 \mathrm{E}-15$ & $1.93 \mathrm{E}-19$ & $2.41 \mathrm{E}-19$ & $4.63 \mathrm{E}-21$ & $2.72 \mathrm{E}-11$ \\
\hline $3 d$ & $1.00 \mathrm{E}-18$ & $5.91 \mathrm{E}-13$ & $1.74 \mathrm{E}-10$ & - & $7.55 \mathrm{E}-12$ & $1.50 \mathrm{E}-15$ & $1.31 \mathrm{E}-17$ & $8.22 \mathrm{E}-18$ & $1.97 \mathrm{E}-19$ & $8.30 \mathrm{E}-12$ \\
\hline $4 p$ & $7.57 \mathrm{E}-19$ & $6.12 \mathrm{E}-13$ & $9.35 \mathrm{E}-11$ & $2.77 \mathrm{E}-11$ & - & $1.50 \mathrm{E}-11$ & $2.08 \mathrm{E}-14$ & $2.31 \mathrm{E}-14$ & $7.31 \mathrm{E}-17$ & $9.04 \mathrm{E}-12$ \\
\hline $5 \mathrm{~s}$ & $1.78 \mathrm{E}-19$ & $9.40 \mathrm{E}-15$ & $4.19 \mathrm{E}-13$ & $1.37 \mathrm{E}-13$ & $3.73 \mathrm{E}-10$ & - & $3.71 \mathrm{E}-13$ & $1.75 \mathrm{E}-13$ & $1.67 \mathrm{E}-15$ & $4.63 \mathrm{E}-13$ \\
\hline $4 d$ & $1.39 \mathrm{E}-21$ & $1.69 \mathrm{E}-18$ & $2.20 \mathrm{E}-17$ & $6.35 \mathrm{E}-16$ & $2.74 \mathrm{E}-13$ & $1.97 \mathrm{E}-13$ & - & $1.90 \mathrm{E}-09$ & $3.43 \mathrm{E}-13$ & $5.85 \mathrm{E}-16$ \\
\hline $4 \mathrm{f}$ & $7.94 \mathrm{E}-22$ & $1.15 \mathrm{E}-18$ & $2.04 \mathrm{E}-17$ & $2.94 \mathrm{E}-16$ & $2.25 \mathrm{E}-13$ & $6.86 \mathrm{E}-14$ & $1.41 \mathrm{E}-09$ & - & $2.08 \mathrm{E}-13$ & $4.75 \mathrm{E}-16$ \\
\hline $5 p$ & $8.32 \mathrm{E}-21$ & $1.22 \mathrm{E}-19$ & $1.26 \mathrm{E}-18$ & $2.26 \mathrm{E}-17$ & $2.29 \mathrm{E}-15$ & $2.10 \mathrm{E}-15$ & $8.16 \mathrm{E}-13$ & $6.69 \mathrm{E}-13$ & - & $7.33 \mathrm{E}-18$ \\
\hline $\mathrm{Na}^{+}+\mathrm{H}^{-}$ & $2.49 \mathrm{E}-15$ & $3.96 \mathrm{E}-10$ & $1.11 \mathrm{E}-07$ & $1.43 \mathrm{E}-08$ & $\begin{array}{c}4.24 \mathrm{E}-09 \\
4000 \mathrm{~K}\end{array}$ & $8.74 \mathrm{E}-12$ & $2.08 \mathrm{E}-14$ & $2.28 \mathrm{E}-14$ & $1.10 \mathrm{E}-16$ & \\
\hline $3 \mathrm{~s}$ & - & $2.02 \mathrm{E}-18$ & $2.28 \mathrm{E}-21$ & $1.43 \mathrm{E}-22$ & $3.76 \mathrm{E}-23$ & $7.97 \mathrm{E}-25$ & $3.28 \mathrm{E}-26$ & $3.09 \mathrm{E}-26$ & $2.07 \mathrm{E}-25$ & $2.61 \mathrm{E}-21$ \\
\hline $3 p$ & $3.02 \mathrm{E}-16$ & - & $1.51 \mathrm{E}-13$ & $1.04 \mathrm{E}-14$ & $3.50 \mathrm{E}-15$ & $5.73 \mathrm{E}-18$ & $4.08 \mathrm{E}-21$ & $3.32 \mathrm{E}-21$ & $9.77 \mathrm{E}-22$ & $4.48 \mathrm{E}-14$ \\
\hline $4 \mathrm{~s}$ & $2.40 \mathrm{E}-17$ & $1.07 \mathrm{E}-11$ & - & $1.99 \mathrm{E}-10$ & $3.79 \mathrm{E}-11$ & $1.49 \mathrm{E}-14$ & $3.16 \mathrm{E}-18$ & $3.29 \mathrm{E}-18$ & $4.19 \mathrm{E}-19$ & $7.03 \mathrm{E}-10$ \\
\hline $3 d$ & $1.04 \mathrm{E}-18$ & $5.03 \mathrm{E}-13$ & $1.37 \mathrm{E}-10$ & - & $9.22 \mathrm{E}-12$ & $4.43 \mathrm{E}-14$ & $1.11 \mathrm{E}-15$ & $6.69 \mathrm{E}-16$ & $4.21 \mathrm{E}-17$ & $6.05 \mathrm{E}-11$ \\
\hline $4 p$ & $6.74 \mathrm{E}-19$ & $4.20 \mathrm{E}-13$ & $6.45 \mathrm{E}-11$ & $2.28 \mathrm{E}-11$ & - & $7.51 \mathrm{E}-11$ & $2.96 \mathrm{E}-13$ & $4.15 \mathrm{E}-13$ & $6.83 \mathrm{E}-15$ & $4.49 \mathrm{E}-11$ \\
\hline $5 \mathrm{~s}$ & $1.23 \mathrm{E}-19$ & $5.93 \mathrm{E}-15$ & $2.19 \mathrm{E}-13$ & $9.46 \mathrm{E}-13$ & $6.48 \mathrm{E}-10$ & - & $4.01 \mathrm{E}-12$ & $1.79 \mathrm{E}-12$ & $3.54 \mathrm{E}-14$ & $1.14 \mathrm{E}-12$ \\
\hline $4 d$ & $1.65 \mathrm{E}-21$ & $1.38 \mathrm{E}-18$ & $1.51 \mathrm{E}-17$ & $7.73 \mathrm{E}-15$ & $8.31 \mathrm{E}-13$ & $1.31 \mathrm{E}-12$ & - & $2.81 \mathrm{E}-09$ & $4.74 \mathrm{E}-12$ & $1.53 \mathrm{E}-15$ \\
\hline $4 f$ & $1.13 \mathrm{E}-21$ & $8.12 \mathrm{E}-19$ & $1.14 \mathrm{E}-17$ & $3.38 \mathrm{E}-15$ & $8.48 \mathrm{E}-13$ & $4.24 \mathrm{E}-13$ & $2.04 \mathrm{E}-09$ & - & $3.00 \mathrm{E}-12$ & $1.58 \mathrm{E}-15$ \\
\hline $5 p$ & $2.08 \mathrm{E}-20$ & $6.56 \mathrm{E}-19$ & $3.99 \mathrm{E}-18$ & $5.83 \mathrm{E}-16$ & $3.82 \mathrm{E}-14$ & $2.30 \mathrm{E}-14$ & $9.44 \mathrm{E}-12$ & $8.21 \mathrm{E}-12$ & - & $6.78 \mathrm{E}-17$ \\
\hline $\mathrm{Na}^{+}+\mathrm{H}^{-}$ & $3.50 \mathrm{E}-15$ & $4.03 \mathrm{E}-10$ & $8.98 \mathrm{E}-08$ & $1.12 \mathrm{E}-08$ & $\begin{array}{c}3.37 \mathrm{E}-09 \\
6000 \mathrm{~K}\end{array}$ & $9.95 \mathrm{E}-12$ & $4.09 \mathrm{E}-14$ & $5.79 \mathrm{E}-14$ & $9.09 \mathrm{E}-16$ & - \\
\hline $3 \mathrm{~s}$ & - & $5.24 \mathrm{E}-17$ & $1.25 \mathrm{E}-19$ & $5.85 \mathrm{E}-21$ & $1.52 \mathrm{E}-21$ & $4.13 \mathrm{E}-23$ & $4.65 \mathrm{E}-24$ & $4.76 \mathrm{E}-24$ & $3.03 \mathrm{E}-23$ & $3.22 \mathrm{E}-19$ \\
\hline $3 p$ & $1.02 \mathrm{E}-15$ & - & $5.55 \mathrm{E}-13$ & $3.74 \mathrm{E}-14$ & $1.27 \mathrm{E}-14$ & $2.77 \mathrm{E}-17$ & $1.20 \mathrm{E}-19$ & $1.72 \mathrm{E}-19$ & $4.01 \mathrm{E}-20$ & $4.66 \mathrm{E}-13$ \\
\hline $4 \mathrm{~s}$ & $6.02 \mathrm{E}-17$ & $1.37 \mathrm{E}-11$ & - & $2.37 \mathrm{E}-10$ & $4.83 \mathrm{E}-11$ & $2.33 \mathrm{E}-14$ & $2.33 \mathrm{E}-17$ & $2.45 \mathrm{E}-17$ & $5.12 \mathrm{E}-18$ & $2.03 \mathrm{E}-09$ \\
\hline $3 d$ & $1.28 \mathrm{E}-18$ & $4.19 \mathrm{E}-13$ & $1.08 \mathrm{E}-10$ & - & $7.87 \mathrm{E}-12$ & $2.28 \mathrm{E}-13$ & $6.94 \mathrm{E}-15$ & $6.06 \mathrm{E}-15$ & $5.61 \mathrm{E}-16$ & $1.13 \mathrm{E}-10$ \\
\hline $4 p$ & $7.24 \mathrm{E}-19$ & $3.09 \mathrm{E}-13$ & $4.78 \mathrm{E}-11$ & $1.71 \mathrm{E}-11$ & - & $1.56 \mathrm{E}-10$ & $1.29 \mathrm{E}-12$ & $1.40 \mathrm{E}-12$ & $5.44 \mathrm{E}-14$ & $7.38 \mathrm{E}-11$ \\
\hline $5 \mathrm{~s}$ & $1.19 \mathrm{E}-19$ & $4.08 \mathrm{E}-15$ & $1.40 \mathrm{E}-13$ & $3.00 \mathrm{E}-12$ & $9.44 \mathrm{E}-10$ & - & $1.11 \mathrm{E}-11$ & $5.94 \mathrm{E}-12$ & $1.84 \mathrm{E}-13$ & $1.69 \mathrm{E}-12$ \\
\hline $4 d$ & $3.71 \mathrm{E}-21$ & $4.91 \mathrm{E}-18$ & $3.87 \mathrm{E}-17$ & $2.53 \mathrm{E}-14$ & $2.16 \mathrm{E}-12$ & $3.08 \mathrm{E}-12$ & - & $3.43 \mathrm{E}-09$ & $1.68 \mathrm{E}-11$ & $3.57 \mathrm{E}-15$ \\
\hline $4 \mathrm{f}$ & $2.75 \mathrm{E}-21$ & $5.07 \mathrm{E}-18$ & $2.94 \mathrm{E}-17$ & $1.60 \mathrm{E}-14$ & $1.70 \mathrm{E}-12$ & $1.19 \mathrm{E}-12$ & $2.48 \mathrm{E}-09$ & - & $1.16 \mathrm{E}-11$ & $3.10 \mathrm{E}-15$ \\
\hline $5 p$ & $4.54 \mathrm{E}-20$ & $3.07 \mathrm{E}-18$ & $1.59 \mathrm{E}-17$ & $3.84 \mathrm{E}-15$ & $1.71 \mathrm{E}-13$ & $9.56 \mathrm{E}-14$ & $3.14 \mathrm{E}-11$ & $3.01 \mathrm{E}-11$ & - & $2.91 \mathrm{E}-16$ \\
\hline $\mathrm{Na}^{+}+\mathrm{H}^{-}$ & $6.22 \mathrm{E}-15$ & $4.62 \mathrm{E}-10$ & $8.16 \mathrm{E}-08$ & $9.94 \mathrm{E}-09$ & $\begin{array}{c}3.01 \mathrm{E}-09 \\
8000 \mathrm{~K}\end{array}$ & $1.13 \mathrm{E}-11$ & $8.66 \mathrm{E}-14$ & $1.04 \mathrm{E}-13$ & $3.76 \mathrm{E}-15$ & - \\
\hline $3 \mathrm{~s}$ & - & $3.77 \mathrm{E}-16$ & $1.35 \mathrm{E}-18$ & $5.00 \mathrm{E}-20$ & $1.25 \mathrm{E}-20$ & $4.13 \mathrm{E}-22$ & $1.01 \mathrm{E}-22$ & $1.03 \mathrm{E}-22$ & $5.00 \mathrm{E}-22$ & $4.95 \mathrm{E}-18$ \\
\hline $3 p$ & $2.66 \mathrm{E}-15$ & - & $1.15 \mathrm{E}-12$ & $6.84 \mathrm{E}-14$ & $2.24 \mathrm{E}-14$ & $6.04 \mathrm{E}-17$ & $1.13 \mathrm{E}-18$ & $2.54 \mathrm{E}-18$ & $6.87 \mathrm{E}-19$ & $1.66 \mathrm{E}-12$ \\
\hline $4 \mathrm{~s}$ & $1.39 \mathrm{E}-16$ & $1.68 \mathrm{E}-11$ & - & $2.40 \mathrm{E}-10$ & $4.77 \mathrm{E}-11$ & $2.80 \mathrm{E}-14$ & $1.17 \mathrm{E}-16$ & $1.79 \mathrm{E}-16$ & $4.34 \mathrm{E}-17$ & $3.43 \mathrm{E}-09$ \\
\hline $3 d$ & $1.90 \mathrm{E}-18$ & $3.69 \mathrm{E}-13$ & $8.88 \mathrm{E}-11$ & - & $7.07 \mathrm{E}-12$ & $6.16 \mathrm{E}-13$ & $1.84 \mathrm{E}-14$ & $2.49 \mathrm{E}-14$ & $3.13 \mathrm{E}-15$ & $1.51 \mathrm{E}-10$ \\
\hline $4 p$ & $9.70 \mathrm{E}-19$ & $2.46 \mathrm{E}-13$ & $3.60 \mathrm{E}-11$ & $1.44 \mathrm{E}-11$ & - & $2.41 \mathrm{E}-10$ & $3.05 \mathrm{E}-12$ & $2.92 \mathrm{E}-12$ & $1.91 \mathrm{E}-13$ & $9.36 \mathrm{E}-11$ \\
\hline $5 \mathrm{~s}$ & $1.62 \mathrm{E}-19$ & $3.36 \mathrm{E}-15$ & $1.07 \mathrm{E}-13$ & $6.36 \mathrm{E}-12$ & $1.23 \mathrm{E}-09$ & - & $2.02 \mathrm{E}-11$ & $1.28 \mathrm{E}-11$ & $6.63 \mathrm{E}-13$ & $2.13 \mathrm{E}-12$ \\
\hline $4 d$ & $1.02 \mathrm{E}-20$ & $1.61 \mathrm{E}-17$ & $1.14 \mathrm{E}-16$ & $4.86 \mathrm{E}-14$ & $3.96 \mathrm{E}-12$ & $5.15 \mathrm{E}-12$ & - & $3.91 \mathrm{E}-09$ & $3.91 \mathrm{E}-11$ & $6.39 \mathrm{E}-15$ \\
\hline $4 \mathrm{f}$ & $7.43 \mathrm{E}-21$ & $2.60 \mathrm{E}-17$ & $1.26 \mathrm{E}-16$ & $4.74 \mathrm{E}-14$ & $2.73 \mathrm{E}-12$ & $2.36 \mathrm{E}-12$ & $2.82 \mathrm{E}-09$ & - & $2.72 \mathrm{E}-11$ & $5.04 \mathrm{E}-15$ \\
\hline $5 p$ & $9.13 \mathrm{E}-20$ & $1.78 \mathrm{E}-17$ & $7.73 \mathrm{E}-17$ & $1.50 \mathrm{E}-14$ & $4.51 \mathrm{E}-13$ & $3.08 \mathrm{E}-13$ & $7.12 \mathrm{E}-11$ & $6.88 \mathrm{E}-11$ & - & $8.48 \mathrm{E}-16$ \\
\hline $\mathrm{Na}^{+}+\mathrm{H}^{-}$ & $1.15 \mathrm{E}-14$ & $5.46 \mathrm{E}-10$ & $7.75 \mathrm{E}-08$ & $9.22 \mathrm{E}-09$ & $2.81 \mathrm{E}-09$ & $1.26 \mathrm{E}-11$ & $1.48 \mathrm{E}-13$ & $1.62 \mathrm{E}-13$ & $1.08 \mathrm{E}-14$ & - \\
\hline
\end{tabular}

the ionic state $\mathrm{Na}(n l)+\mathrm{H}(1 \mathrm{~s}) \rightleftharpoons \mathrm{Na}^{+}\left(2 \mathrm{~s}^{2} 2 \mathrm{p}^{6}\right)+\mathrm{H}^{-}$, are presented in Table 1 . The coefficients have been obtained by folding the cross-sections with a Maxwellian velocity distribution from threshold to $100 \mathrm{eV}$, and are presented for temperatures in the range $500-8000 \mathrm{~K}$.
The $500 \mathrm{~K}$ data are provided since there is substantial interest in $\mathrm{Na}$ lines in low temperature astrophysical environments such as brown dwarfs and planetary atmospheres (e.g. Burrows et al. 2001; Barman et al. 2002), and though other perturbers such as $\mathrm{H}_{2}$ and $\mathrm{He}$ are usually more abundant in these 
situations, the data may be useful. Lin et al. (2008) have recently calculated data for inelastic processes in $\mathrm{Na}+\mathrm{He}$ collisions with application to planetary and brown dwarf atmospheres in mind. However, the main driver behind our study is the need for data for line formation modelling in F, G and $\mathrm{K}$ star atmospheres where ground state hydrogen atoms are indeed the most abundant perturber. Thus, our discussion below will predominantly focus on the $2000-8000 \mathrm{~K}$ data.

Although the data for inverse processes are related via the detailed-balance relation and thus redundant, little space can be saved by omitting one of the two and so we present data for both, thus saving the end user the need to make such calculations themselves. It is worth noting that the excitation and ion-pair production processes were calculated directly from the crosssections, while deexcitation and mutual-neutralisation processes were calculated via the detailed-balance relation rather than direct calculation from the deexcitation cross-sections. As for $\mathrm{Li}$ (Barklem et al. 2003), for the temperatures most relevant for cool stars around $6000 \mathrm{~K}$, it is readily seen that the rate coefficients for ion-pair production are remarkably large, particularly from the first excited $s$ state, here $4 s$. Some rates between closetogether neighbouring levels, such as $4 \mathrm{~s} \rightarrow 3 \mathrm{~d}$ and $4 \mathrm{~d} \rightarrow 4 \mathrm{f}$ are also seen to be very large. At low temperatures, the rate coefficients for these transitions with small energy thresholds become by far the largest.

In Belyaev et al. (2010) it was shown that narrow orbiting and Feshbach resonances are often present in the cross-sections at low energy (see Figs. 5, 8 and 9 of that paper). To fully resolve these features requires calculations with very small steps in collision energy, which is extremely time consuming. Such detailed calculations were performed for the $3 \mathrm{~s} \rightarrow 3 \mathrm{p}$ cross-sections in order to resolve a significant fraction of the orbiting resonances. This further allowed pure background cross-sections, i.e. with no resonances, to be constructed for this transition. From these calculations it was estimated that the contribution of the resonances to the rate coefficient was roughly $33 \%$ at $500 \mathrm{~K}, 20 \%$ at $2000 \mathrm{~K}$, $15 \%$ at $5000 \mathrm{~K}$ and $10 \%$ at $8000 \mathrm{~K}$. The rate coefficients for $3 \mathrm{~s} \rightarrow 3 \mathrm{p}$ presented here are calculated including the contribution of orbiting resonances. In all other cases, the cross-section calculations were performed using an energy grid with steps much greater than the widths of the resonances. Consequently most resonances are missed and those resonances that are by chance sampled are not resolved. Missed resonances will lead to an underestimate of the contribution of the rate coefficient, while unresolved resonances will generally lead to an overestimate of the contribution since the widths of the resonances are significantly overestimated, and this may lead to some cancellation of errors. In any case, the error in the rate coefficients from this source of uncertainty should not exceed the magnitude of the corrections given above for $3 \mathrm{~s} \rightarrow 3 \mathrm{p}$, i.e. of order $10 \%$, which is significantly less than the uncertainties from other sources discussed below.

The accuracy of these rate coefficients is determined by the accuracy of the cross-sections near the threshold. At $T=2000 \mathrm{~K}$ the values of the rate coefficients vary from $10^{-31}$ to $10^{-9} \mathrm{~cm}^{3} / \mathrm{s}$, more than 20 orders of magnitude. At $T=8000 \mathrm{~K}$ the variation is from $10^{-22}$ to $10^{-9} \mathrm{~cm}^{3} / \mathrm{s}, 13$ orders of magnitude. This reflects the fact that at the collision energies of interest the nonadiabatic transition probabilities also vary by similar factors, and that many of them have extremely small values. These small transition probabilities are sensitive to variations in both the input quantum chemical data (potentials and couplings) and the method employed for solving the coupled channel equations in the quantum scattering calculations ${ }^{1}$. In addition, transitions can occur in symmetries other than ${ }^{1} \Sigma^{+}$: for example, in the singlet system the $p-, d-$, and $f$-states can populate the ionic state via rotational couplings between $\Pi$ and $\Sigma$ states, as well as excite other states due to both rotational and radial nonadiabatic couplings in $\Pi, \Delta$, and other symmetries. The same is true for the triplet system with larger (at least by a factor of 3 ) initial statistical probabilities. For example, the cross-sections for $3 \mathrm{~s} \rightarrow 3 \mathrm{p}$ excitation and their sensitivity to the input quantum chemical data are discussed at length in Belyaev et al. (2010), where we have shown that the results may vary by a factor of about 100 . Similarly, from our investigations it is possible to make estimates of how much rate coefficients might vary for all transitions, and thus we define a "fluctuation factor" representing an estimate of this variation and which is somewhat analogous to an estimate of the uncertainty. The probable range for a given rate coefficient can be estimated to be from the value given in Table 1 multiplied by the minimum value of the fluctuation factor, up to the same value multiplied by the maximum value of the fluctuation factor, noting that from the arguments discussed above, particularly contributions from other symmetries, it is generally more likely that the rate coefficient would be increased rather than decreased.

We have assembled estimates of these fluctuation factors for all transitions in Table 2. A common feature of the quantum scattering calculations, particularly for very adiabatic transitions, is that the sensitivity of the cross-sections to the input quantum chemistry data usually decreases with increasing collision energy, and thus cross-sections are often most uncertain very close to threshold, becoming less uncertain with increasing collision energy. This means that rate coefficients are usually most uncertain at low temperatures, becoming less uncertain at higher temperatures. Thus, in some cases we provide a range of fluctuation factors corresponding to the lower and higher ends of the temperature range considered. The rate coefficient for $3 \mathrm{~s} \rightarrow 3 \mathrm{p}$ excitation is roughly $10^{-21} \mathrm{~cm}^{3} / \mathrm{s}$ at $2000 \mathrm{~K}$, somewhere in the middle of the range for all transitions. Thus, it is quite natural to expect that fluctuation factors for transitions with small transition probabilties can be much larger than 100, while the fluctuation coefficients for the transitions determined by large transition probabilities should be close to unity.

It is worth making clear that the smallest rate coefficients usually have the largest fluctuation factors: even if these rates were multiplied by such a large fluctuation factor they would not become dominant or substantially change the general pattern of relative strengths between different transitions. Nevertheless, for astrophysical applications it might be important to have such estimates of the possible uncertainties for the rate coefficients in order to see if any such transitions could have effects and thus warrant more accurate study.

These calculations have been employed to determine the total rate coefficient for mutual neutralization. This rate coefficient can be approximated as $2.44 \times 10^{-7}(300 \mathrm{~K} / T)^{0.32} \mathrm{~cm}^{3} / \mathrm{s}$ with an error of less than $5 \%$ for $500 \leq T \leq 8000 \mathrm{~K}$. This new result can be up to $50 \%$ larger than that given by Dickinson et al. (1999): the difference is primarily because a very much finer energy grid has been employed in the Belyaev et al. (2010) work.

\footnotetext{
1 Note, in Belyaev et al. (2010) we found satisfactory agreement between two different methods and codes when calculating cross-sections for the $3 \mathrm{~s} \rightarrow 3 \mathrm{p}$ and $4 \mathrm{~s}$ transitions. These transitions have reasonably large cross-sections. However, recent additional calculations have shown some differences between calculations for transitions with much smaller cross-sections.
} 
Table 2. Estimated maximum values of the "fluctuation factors" (a measure of the uncertainty) in the rate coefficients, given as factors of the rate coefficients in Table 1.

\begin{tabular}{cccccccccc}
\hline \hline $\begin{array}{c}\text { Initial } \\
\text { state } n l\end{array}$ & $3 \mathrm{p}$ & $4 \mathrm{~s}$ & $3 \mathrm{~d}$ & $4 \mathrm{p}$ & $5 \mathrm{~s}$ & $4 \mathrm{~d}$ & $4 \mathrm{f}$ & $5 \mathrm{p}$ & $\mathrm{Na}^{+}+\mathrm{H}^{-}$ \\
\hline $3 \mathrm{~s}$ & $120-70$ & $50-10$ & 10 & 20 & $100-10$ & $100-10$ & $100-10$ & $10^{3}-100$ & 2 \\
$3 \mathrm{p}$ & & 2 & 5 & 2 & $5-3$ & $100-10$ & $10^{3}-30$ & $10^{5}-100$ & 2 \\
$4 \mathrm{~s}$ & & & 6 & 2 & $100-10$ & $10^{4}-400$ & $10^{4}-100$ & $10^{5}-10^{3}$ & 2 \\
$3 \mathrm{~d}$ & & & & 2 & $20-2$ & $100-20$ & $10-2$ & $10^{4}-2$ & $2-3$ \\
$4 \mathrm{p}$ & & & & & 2 & 2 & 2 & 2 & 2 \\
$5 \mathrm{~s}$ & & & & & & 2 & 2 & $100-2$ & 10 \\
$4 \mathrm{~d}$ & & & & & & & 2 & $10^{3}-2$ & $10^{4}-100$ \\
$4 \mathrm{f}$ & & & & & & & & $10-2$ & $100-40$ \\
$5 \mathrm{p}$ & & & & & & & & $10^{4}-30$ \\
\hline
\end{tabular}

Notes. The minimum value is estimated to be 0.5 in all cases. If a range is given, the first number corresponds to $2000 \mathrm{~K}$ and the second the $8000 \mathrm{~K}$ temperature result. For example, if the table lists 10-2, then the maximum fluctuation factor in the rate coefficient is estimated to be 10 near $2000 \mathrm{~K}$ and 2 near $8000 \mathrm{~K}$.

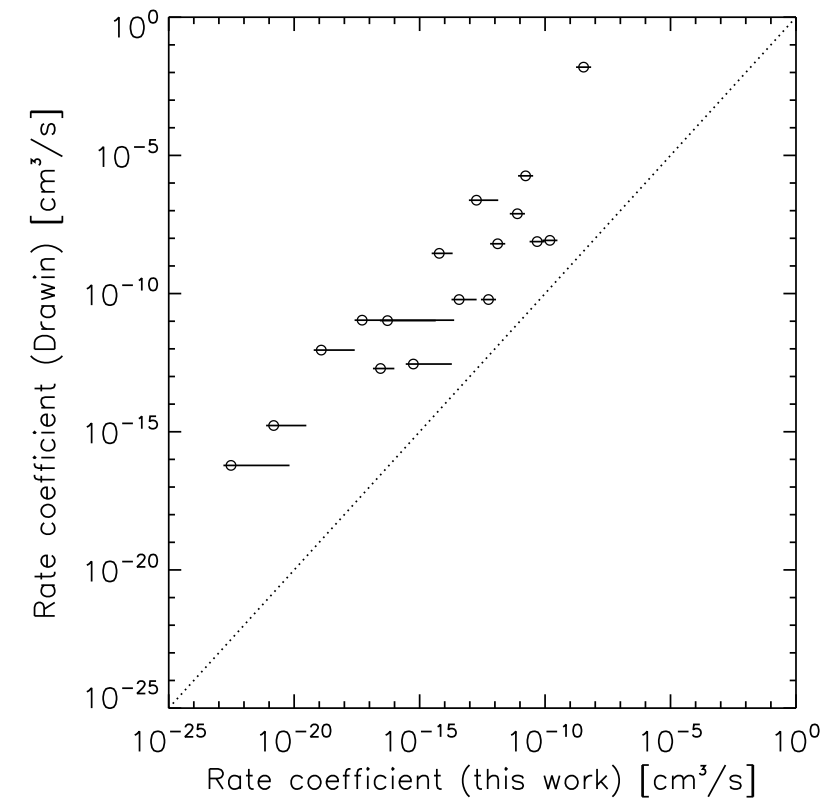

Fig. 1. Comparison of rate coefficients at $6000 \mathrm{~K}$ from the Drawin formula (y-axis) with those from this work ( $x$-axis). The dotted line is the one-to-one relation. The horizontal lines show the range in our values implied by the fluctuation factors, which are taken from Table 2 and log-interpolated at $6000 \mathrm{~K}$ between the extremes if a range is given.

\section{Discussion}

The rate coefficients show a general pattern similar to that found for $\mathrm{Li}+\mathrm{H}$ collisions (Barklem et al. 2003), with large rates for charge exchange processes, particularly from the first excited $s$ state, and comparatively small rates for excitation processes, except in the cases of transitions between neighbouring excited levels. One may therefore reasonably expect similar effects on the statistical equilibrium calculations from inclusion of these processses: i.e. excitation and deexcitation processes have little or negligible effect, while charge exchange processes have significant effects. It is, however, important that this be confirmed via detailed statistical equilibrium calculations.

Regarding comparison of these data with those from the commonly used Drawin formula (Steenbock \& Holweger 1984;
Drawin 1968; Drawin \& Emard 1973), the situation is again similar to that for Li. The Drawin formula gives rate coefficients for optically allowed transitions (the Drawin formula cannot be used for optically forbidden transitions or charge exchange) between one and seven orders of magnitude larger than the results presented here, see Fig. 1. Note that there is some correlation between the Drawin results and ours which simply stems from the fact that the Drawin formula correctly accounts for the fact that transitions with smaller energy thresholds will have larger rate coefficients. In any case there is a scatter of some six orders of magnitude around this correlation and a significant offset. We also note that the differences cannot be explained within the estimated fluctuation factors for the results, and in addition there is no correlation between the difference and the uncertainty in our rate coefficient.

Acknowledgements. We gratefully acknowledge the support of the Royal Swedish Academy of Sciences, Göran Gustafssons Stiftelse and the Swedish Research Council. P.S.B. is a Royal Swedish Academy of Sciences Research Fellow supported by a grant from the Knut and Alice Wallenberg Foundation. A.K.B. gratefully acknowledges the support from the Russian Foundation for Basic Research (Grant No. 10-03-00807-a).

\section{References}

Asplund, M. 2005, ARA\&A, 43, 481

Barklem, P. S., Belyaev, A. K., \& Asplund, M. 2003, A\&A, 409, L1

Barman, T. S., Hauschildt, P. H., Schweitzer, A., et al. 2002, ApJ, 569, L51

Belyaev, A. K., \& Barklem, P. S. 2003, Phys. Rev. A, 68, 062703

Belyaev, A. K., Grosser, J., Hahne, J., \& Menzel, T. 1999, Phys. Rev. A, 60, 2151

Belyaev, A. K., Barklem, P. S., Dickinson, A. S., \& Gadéa, F. X. 2010, Phys. Rev. A, 81, 032706

Burrows, A., Hubbard, W. B., Lunine, J. I., \& Liebert, J. 2001, Rev. Mod. Phys., 73,719

Croft, H., Dickinson, A. S., \& Gadéa, F. X. 1999, J. Phys. B, 32, 81

Dickinson, A. S., Poteau, R., \& Gadéa, F. X. 1999, J. Phys. B, 32, 5451

Drawin, H. W. 1968, Z. Phys., 211, 404

Drawin, H. W., \& Emard, F. 1973, Phys. Lett. A, 43, 333

Fleck, I., Grosser, J., Schnecke, A., Steen, W., \& Voigt, H. 1991, J. Phys. B, 24, 4017

Kiselman, D. 2001, New Astron. Rev., 45, 559

Lambert, D. L. 1993, Phys. Scr., Vol. T, 47, 186

Lin, C. Y., Stancil, P. C., Liebermann, H.-P., Funke, P., \& Buenker, R. J. 2008, Phys. Rev. A, 78, 052706

Lind, K., Asplund, M., \& Barklem, P. S. 2009, A\&A, 503, 541

Steenbock, W., \& Holweger, H. 1984, A\&A, 130, 319 